\section{Doação de gametas: questões sociais e éticas (não) respondidas em Portugal}

\author{
Gamete donation: (un)answered social and \\ ethical issues in Portugal
}

\section{Donación de gametos: cuestiones sociales y éticas (no) respondidas en Portugal}

\section{Resumo}

Conhecer a discussão em torno dos desafios sociais e éticos da doação de gametas é fundamental para a boa governança das técnicas de reprodução assistida. Neste artigo, analisam-se os tópicos que orientaram o debate nas organizações de ética portuguesas, discutindo as suas conexões com os temas abordados internacionalmente. Para tal, em março de 2018, pesquisamos sistematicamente os websites do Conselho Nacional de Procriação Medicamente Assistida e do Conselho Nacional de Ética para as Ciências da Vida. Procedemos à análise de conteúdo temática de 25 documentos. Os resultados indicam que o debate se centrou na acessibilidade, no anonimato e na compensação de doadores $e$, em menor extensão, nas responsabilidades profissionais. Observaram-se posicionamentos heterogêneos e tensões entre múltiplos direitos e princípios éticos associados a receptores, a pessoas nascidas com recurso à doação de gametas e a doadores. Esses têm em comum três alegações: a escassez de evidência científica; as experiências de outros países; e regulamentações oriundas de entidades internacionais. Na literatura abordam-se tópicos adicionais, nomeadamente: uma via dupla que conjugue anonimato/identificação de doadores; implementação de sistemas de registo reprodutivo para receptores e doadores; limites do rastreio genético a doadores; doação por familiares/conhecidos; e o papel dos doadores na decisão quanto ao destino de embriões criopreservados e na escolha das características dos receptores dos seus gametas. Há espaço para expandir o debate e promover a pesquisa em torno das implicações sociais e éticas da doação de gametas, considerando a participação de todos os cidadãos.

Técnicas de Reprodução Assistida; Bioética; Concepção de Doadores;

Participação da Comunidade; Governança
Sandra Pinto da Silva 1,2

Cláudia De Freitas 1,2,3

Inês Baía 1,2

Catarina Samorinha 1,2

Helena Machado 4

Susana Silva 1,2

doi: 10.1590/0102-311X00122918

\author{
Correspondência \\ S. Pinto da Silva \\ EPIUnit - Instituto de Saúde Pública, Universidade do Porto. \\ Rua das Taipas 135, Porto, 4050-600, Porto, Portugal. \\ sandra.silva@ispup.up.pt \\ 1 Instituto de Saúde Pública, Universidade do Porto, Porto, \\ Portugal. \\ 2 Faculdade de Medicina, Universidade do Porto, Porto, \\ Portugal. \\ 3 Centro de Investigação e Estudos em Sociologia, ISCT-Instituto \\ Universitário de Lisboa, Lisboa, Portugal. \\ 4 Instituto de Ciências Sociais, Universidade do Minho, Braga, \\ Portugal.
}




\section{Introdução}

As biotecnologias associadas ao início da vida humana levantam inúmeras questões sociais e éticas 1 , particularmente as que se situam na interface da reprodução assistida e da genética reprodutiva ${ }^{2}$. É o caso da doação de gametas, em que a discussão tem focalizado em três tópicos principais 3 . Primeiro, as diferentes configurações de responsabilidades individuais, familiares e coletivas que resultam da diversidade de políticas, de regulamentações e de práticas existentes em nível global. Há diferentes regimes de anonimato e de identificação de doadores 4,5,6. Os processos de decisão dos receptores em relação à revelação e à partilha de informação sobre o seu envolvimento na doação de gametas são multifacetados 7,8. Há divergências quanto ao papel dos doadores na obtenção de consentimento na doação de embriões criados por doação de gametas para pesquisa científica 9,10. Segundo, as boas práticas nos sistemas de recrutamento e seleção de doadores, com um foco nos processos de rastreio médico, genético e psicossocial de doadores, na legitimidade moral e ética de diferentes modalidades de compensação e na avaliação do investimento em campanhas de sensibilização para a doação 11,12. Por fim, as desigualdades no acesso a técnicas de reprodução assistida heterólogas e as respectivas implicações para a circulação de gametas e de receptores, assim como de profissionais de saúde e de doadores, discutindo-se, sobretudo, o desenvolvimento de sistemas que permitam assegurar a segurança, qualidade e eficácia dos cuidados de saúde transfronteiriços 13,14.

Em Portugal, a primeira legislação a regular a reprodução assistida data de julho de 2006, contemplando o acesso à doação de gametas por parte de casais heterossexuais casados (ou em união estável) com um diagnóstico de infertilidade, assegurando o anonimato dos doadores 15,16. Recentemente, a promoção da igualdade e da equidade no acesso a técnicas de reprodução assistida, assim como o evitamento da procura transfronteiriça de cuidados de saúde nesta área, constituíram tópicos privilegiados de discussão na governança da doação de gametas. Essa discussão criou espaço para que, em 2016, o acesso a essas técnicas fosse autorizado independentemente de um diagnóstico de infertilidade, do estado civil ou orientação sexual das receptoras 15,17, o que é permitido no Brasil desde 201318. A viabilidade do alargamento do acesso a todas as mulheres nos centros públicos foi equacionada, considerando os recursos humanos e financeiros disponíveis e o número limitado de doações para o único banco público de gametas existente em Portugal desde 2011 3. Para responder a um aumento da demanda de gametas e diminuir a importação de células reprodutivas pelos centros públicos, em janeiro de 2017 foram inaugurados dois novos centros de colheita de gametas 19. Atualmente, existem quatro centros públicos e 15 privados com doação de gametas. Procurou-se, ainda, promover o envolvimento de diferentes entidades da sociedade civil que desenvolvem trabalho na área das técnicas de reprodução assistida por intermédio da implementação de uma campanha nacional de informação e divulgação sobre a doação de gametas 19, tendo sido lançada a primeira página online do Serviço Nacional de Saúde sobre esta temática 20. Em maio de 2018, o Tribunal Constitucional Português declarou a inconstitucionalidade do anonimato dos doadores de gametas 21 , contrariando a norma da maioria dos países, incluindo o Brasil 22.

Subsistem, ainda, desafios sociais e éticos complexos e urgentes que não foram completamente debatidos em Portugal 3. A análise de contextos nacionais à luz da literatura internacional contribui para enriquecer o debate científico e o conhecimento de profissionais de saúde, fomentando a reflexão crítica sobre temas e políticas públicas que repercutem no cuidado de saúde das populações. Disseminar essa informação é fundamental para que todos os receptores e doadores estejam conscientes das implicações sociais e éticas da doação de gametas, a curto e longo prazo 15,23,24, e para que a sociedade civil possa se pronunciar sobre as implicações inerentes a potenciais alterações num campo social, ético e legislativo tão dinâmico como é o caso das técnicas de reprodução assistida 3 . A análise das similitudes e diferenças entre as discussões e os temas abordados em níveis nacional e internacional é particularmente importante nesse contexto científico 2 e regulatório em constante mutação 21,22, na medida em que contribui para a compreensão dos seus usos sociais 25 e constitui uma estratégia para antecipar potenciais desafios, riscos, incertezas e controvérsias. Além disso, entrecruzar as problemáticas que adquirem relevância num contexto nacional com os tópicos que orientam a discussão internacional é fundamental para promover um debate crítico, plural e inclusivo 26, em que a participação de todos os atores envolvidos na doação de gametas - elemento fundamental da boa 
governança 27,28 - é essencial para conceber e implementar políticas e cuidados de saúde centrados nas pessoas 29,30 .

Logo, este artigo pretende analisar os tópicos que têm orientado o debate em torno das implicações sociais e éticas da doação de gametas nas principais organizações de ética portuguesas no âmbito das ciências da saúde e da vida. Esses resultados serão posteriormente discutidos à luz dos tópicos em debate nos documentos emitidos pelas duas sociedades que, em nível mundial, são líderes na área da medicina reprodutiva: a Sociedade Europeia de Reprodução Humana e Embriologia (European Society of Human Reproduction and Embryology - ESHRE) 31 e a Sociedade Americana de Medicina Reprodutiva (American Society for Reproductive Medicine - ASRM) 32.

\section{Métodos}

Em março de 2018, foram identificados os documentos produzidos sobre doação de gametas pelos dois principais órgãos independentes portugueses que se pronunciam sobre as questões éticas suscitadas pela inovação tecnológica e científica no campo das ciências da saúde e da vida, em geral, e as questões éticas, sociais e legais suscitadas pelas técnicas de reprodução assistida, em particular: o Conselho Nacional de Ética para as Ciências da Vida (CNECV) e o Conselho Nacional de Procriação Medicamente Assistida (CNPMA), respetivamente. Criado em 1990 e funcionando junto à Assembleia da República Portuguesa desde 2009, os atuais 20 membros do CNECV procuram refletir com vista à elaboração de documentos de estudo e pareceres (relatórios e eventuais declarações de voto), enquanto promovem o diálogo com a sociedade. Os nove membros do CNPMA asseguram, desde 2006, a supervisão, acompanhamento e avaliação da pesquisa e das práticas na reprodução assitida, formulando recomendações não vinculativas, deliberações vinculativas e emitindo pareceres e outros documentos visando à adequação da reprodução assistida à evolução científica, tecnológica, cultural e social.

A identificação dos documentos elegíveis foi realizada por intermédio de uma pesquisa sistemática no separador "Pareceres" do website do CNECV 33 e no separador "Documentação" do website do CNPMA 34. Após a exclusão dos documentos que apenas descreviam procedimentos, requisitos e parâmetros de funcionamento dos centros de reprodução assistida, assim como dos modelos de consentimento informado, relatórios e planos de atividade, e dos pareceres sobre pedidos de licenciamento e autorização de centros de reprodução assistida, recolheram-se 148 documentos. O conjunto de documentos - parecer, relatório e/ou declarações de voto - emitidos com o mesmo código de identificação foi contabilizado como apenas um documento.

Selecionaram-se para análise os documentos que: (i) incluíam pelo menos uma das seguintes palavras (ou respectivo cognato): célula, gameta, ovócito, óvulo, esperma e doador; e (ii) referiam implicações sociais e éticas associadas à doação de gametas. Reuniram-se, dessa forma, 25 documentos emitidos pelo CNECV (12 relatórios-pareceres) e pelo CNPMA (9 deliberações, 2 recomendações e 2 pareceres) entre 1993 e 2017 (Tabela 1). O fluxograma da pesquisa documental está descrito na Figura 1.

A análise de conteúdo temática 35 foi realizada por duas autoras, de forma independente, recorrendo ao software NVivo 11 (https://www.qsrinternational.com/nvivo/home). Com base numa abordagem indutiva, foram codificados todos os direitos e princípios éticos enumerados nos documentos, assim como os argumentos utilizados para sustentar os posicionamentos em relação aos temas em debate que emergiram da leitura dos documentos. As categorizações foram comparadas e discutidas até haver consenso, envolvendo uma terceira autora no processo de revisão e redefinição consecutiva do modelo de análise final. Foram selecionados os extratos mais ilustrativos dos direitos, princípios éticos e argumentos usados no debate em torno das implicações sociais e éticas da doação de gametas para a apresentação na seção de resultados. 
Tabela 1

Lista dos 25 documentos analisados.

\begin{tabular}{|c|c|c|c|c|}
\hline Código & Emissor & Ano de publicação & Temática & Tipo de documento \\
\hline D1 & CNECV & 1993 & Reprodução assistida & $\begin{array}{l}\text { Relatório-parecer (3/CNECV/93) com } \\
3 \text { declarações de voto }\end{array}$ \\
\hline D2 & CNECV & 1995 & Experimentação do embrião & Relatório-parecer (15/CNECV/95) \\
\hline D3 & CNECV & 1996 & Obrigatoriedade dos testes de aids & Relatório-parecer (16/CNECV/96) \\
\hline D4 & CNECV & 1997 & Reprodução assistida & $\begin{array}{l}\text { Relatório-parecer (23/CNECV/97) com } \\
\qquad 2 \text { declarações de voto }\end{array}$ \\
\hline D5 & CNECV & 2001 & Implicações éticas da genômica & Relatório-parecer (40/CNECV/2001) \\
\hline D6 & CNECV & 2004 & Reprodução assistida & $\begin{array}{l}\text { Relatório-parecer (44/CNECV/2004) com } \\
11 \text { declarações de voto }\end{array}$ \\
\hline D7 & CNPMA & 2009 & Instalação de um centro público de gametas & Recomendação \\
\hline D8 & CNPMA & 2010 & $\begin{array}{c}\text { Atribuição de compensações aos doadores } \\
\text { de células reprodutivas }\end{array}$ & Recomendação \\
\hline D9 & CNPMA & 2010 & $\begin{array}{l}\text { Promoção e publicidade da dádiva } \\
\text { de células reprodutivas }\end{array}$ & Deliberação (Deliberação no 05/2010) \\
\hline D10 & CNECV & 2012 & Reprodução assistida e útero de substituição & $\begin{array}{l}\text { Relatório-parecer (63/CNECV/2012) com } \\
\qquad 4 \text { declarações de voto }\end{array}$ \\
\hline D11 & CNPMA & 2013 & $\begin{array}{l}\text { Admissibilidade do recurso a embriões doados face } \\
\text { a limitações no acesso a técnicas de reprodução } \\
\text { assistida no âmbito do Sistema Nacional de Saúde }\end{array}$ & Deliberação (Deliberação no 04/II, 2013) \\
\hline D12 & CNPMA & 2013 & $\begin{array}{l}\text { Admissibilidade do recurso à inseminação intrauterina } \\
\text { com sêmen de doador quando o elemento feminino } \\
\text { do casal é portador de doença viral }\end{array}$ & Deliberação (Deliberação no 05/II, 2013) \\
\hline D13 & CNPMA & 2013 & $\begin{array}{l}\text { Registo da atribuição das compensações } \\
\text { aos doadores }\end{array}$ & Deliberação (Deliberação no 06/II, 2013) \\
\hline D14 & CNECV & 2014 & $\begin{array}{l}\text { Qualidade e segurança relativa à dádiva, } \\
\text { colheita, análise, processamento, preservação, } \\
\text { armazenamento, distribuição e aplicação de células } \\
\text { de origem humana }\end{array}$ & Relatório-parecer (79/CNECV/2014) \\
\hline D15 & CNPMA & 2014 & Distribuição/importação de células reprodutivas & Deliberação (Deliberação no 07/II, 2014) \\
\hline D16 & CNPMA & 2015 & $\begin{array}{l}\text { Promoção e publicidade da atividade dos centros de } \\
\text { reprodução assistida }\end{array}$ & Deliberação (Deliberação no 10/II, 2015) \\
\hline D17 & CNECV & 2016 & Reprodução assistida e útero de substituição & $\begin{array}{c}\text { Relatório-parecer com } 3 \text { declarações de voto } \\
\text { (87/CNECV/2016) }\end{array}$ \\
\hline D18 & CNECV & 2016 & Codificação de células de origem humana & Relatório-parecer (88/CNECV/2016) \\
\hline D19 & CNPMA & 2016 & Reprodução assistida & $\begin{array}{l}\text { Parecer (sugestões de textos legislativos e } \\
\text { fundamentação das sugestões) com } \\
1 \text { declaração de voto }\end{array}$ \\
\hline D20 & CNPMA & 2016 & Reprodução assistida & $\begin{array}{l}\text { Parecer (decreto-lei que procede a } \\
\text { regulamentação da Lei no 17/2016) }\end{array}$ \\
\hline D21 & CNECV & 2016 & Reprodução assistida & Relatório-parecer (90/CNECV/2016) \\
\hline D22 & CNECV & 2017 & Qualidade e segurança de células & Relatório-parecer (93/CNECV/2017) \\
\hline D23 & CNPMA & 2017 & Recurso à fertilização recíproca & Deliberação (Deliberação noo 13-II/2017) \\
\hline D24 & CNPMA & 2017 & Limite etário de mulheres receptoras & $\begin{array}{l}\text { Deliberação (Deliberação no 15-II/2017) com } \\
1 \text { declaração de voto }\end{array}$ \\
\hline D25 & CNPMA & 2017 & Limite etário de homens receptores & Deliberação (Deliberação no 16-II/2017) \\
\hline
\end{tabular}

CNECV: Conselho Nacional de Ética para as Ciências da Vida; CNPMA: Conselho Nacional de Procriação Medicamente Assistida.

Fonte: documentos emitidos pelo CNECV 33 e pelo CNPMA 34 sobre as implicações sociais e éticas da doação de gametas. 


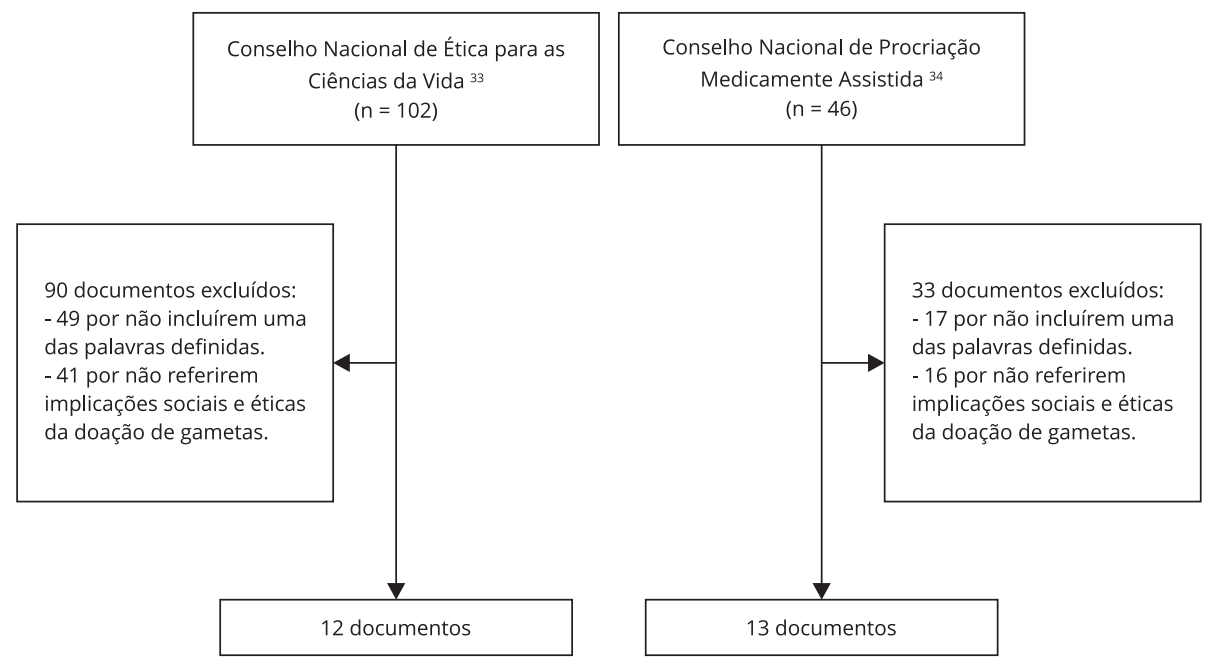

\section{Resultados}

Nas principais organizações de ética portuguesas, o debate sobre as implicações sociais e éticas da doação de gametas gravitou em torno de três tópicos: acessibilidade à doação de gametas; regimes de anonimato e compensação de doadores; e responsabilidades dos profissionais.

\section{Acessibilidade à doação de gametas}

No Quadro 1 estão os extratos ilustrativos dos principais tópicos discutidos no âmbito da acessibilidade à doação de gametas, que constituiu um dos principais temas em debate nos documentos analisados. Discutiu-se a aceitabilidade da doação de gametas, contextualizando-a em situações que terão potenciado a dissociação entre sexo e procriação e entre parentalidade biológica e social, como "o uso generalizado dos métodos contraceptivos" e o "aumento de divórcios", respetivamente [A1.a]. Essas circunstâncias terão facilitado a aceitação "mimética e acrítica" da reprodução assistida heteróloga [A1.a]. Realçou-se, nesse contexto, a necessidade de promover uma reflexão coletiva [A1.b], de desenvolver estudos sobre a doação de gametas [A1.c; A1.d] e de uniformizar com coerência a aplicação de princípios éticos [A1.e] perante a diversidade de regulamentações internacionais [A1.f]. O CNECV considerou importante desenvolver uma reflexão "partilhada pelo maior número possível de cidadãos" [A1.b], mas o CNPMA entendeu que "a totalidade da representatividade da vontade popular" está concentrada na Assembleia da República Portuguesa [A1.g].

Uma outra discussão girou em torno da definição de prioridades em saúde, entrecruzando a valorização relativa da liberdade e da autonomia individuais [A2.a], da equidade no acesso a cuidados de saúde [A2.b], do aparente sucesso de alternativas para "superar a ausência de filhos" [A2.c] e das experiências de outros países quanto às "políticas de apoio à parentalidade" [A2.d]. Defendeu-se a priorização de "opções sociais", salientando-se a adoção, e de "programas de prevenção (da infertilidade), de educação para a saúde e para a sexualidade e serviços de aconselhamento da população” [A2.c] incluídos nos cuidados de saúde primários [A2.e]. No entanto, a aceitabilidade ética dessas propostas foi questionada com base na importância de investir nas técnicas de reprodução assistida face ao envelhecimento populacional e por coerência com a situação da interrupção voluntária da gravidez 


\section{Quadro 1}

Extratos sobre as responsabilidades dos profissionais envolvidos na doação de gametas.

A1. Aceitabilidade da doação de gametas (dissociação sexo-procriação e entre parentalidade biológica e social; necessidade de reflexão e de estudos sobre dimensões socioéticas e técnicas; existência de enquadramentos jurídicos distintos e necessidade de uniformização de princípios éticos).

[A1.a] "O uso generalizado dos métodos contraceptivos dissociou (...) relacionamento sexual e procriação (...) levando a uma atitude sexual mais permissiva, que disporá a sociedade para a aceitação da reprodução medicamente assistida com dadores (...). Estas situações [aumento de divórcios] (...) facilitam a aceitação da dissociação entre paternidade ou maternidade biológicas e sociais, que se verificam na reprodução medicamente assistida com dadores. (...) A reprodução heteróloga (...) foi-se generalizando de forma mimética e acrítica, sem que se tivesse deixado lugar para a reflexão independente e esclarecida a que uma sociedade livre tem direito" (D1).

[A1.b] "O CNECV considera importante continuar a desenvolver uma reflexão ética que possa ser partilhada pelo maior número possível de cidadãos que integram a nossa sociedade plural" (D17).

[A1.C] "O CNECV recomenda (...) que sejam promovidos estudos longitudinais e registos para aquisição de evidência sobre a informação inerente às diversas facetas (não apenas técnicas) da procriação medicamente assistida" (D10).

[A1.d] “Lamenta-se a ausência de estudos (...) sobre (...) condições na aquisição de gametas (...). Os dados concernentes ao número de (...) técnicas com recurso a dador são publicados (...); todavia, (...) os dados sobre os partos oriundos por centro não são individualizados (...). Se alguns destes dados são do conhecimento do CNPMA - como a Lei assim determina - não se vislumbra por que razões ou motivos (...) se mantém tão grande secretismo" (D10).

[A1.e] "Muitas leis admitem a dádiva, por terceiros, de ovócitos e de esperma (...). Há legislações que proíbem a dádiva de esperma e de ovócitos, como por exemplo a Áustria e a Noruega, a par de outras que apenas vedam a utilização de ovócitos de terceiros, como por exemplo a Suíça. (...) No entanto, o Parlamento Europeu na Recomendação (...) de 16 de março de 1989 declarou indesejáveis todas as formas de reprodução heteróloga" (D6).

[A1.f] "A implementação de um sistema uniformizado de codificação [de dadores e receptores] (...) com a salvaguarda da segurança e confidencialidade de dados pessoais, contribui para o intercâmbio [transfronteiriço] e a justa distribuição do material biológico de origem humana (...). É necessária, também do ponto de vista ético, a uniformização e coerência dos princípios que se aplicam a situações idênticas" (D18).

[A1.g] "É na Assembleia da República que se encontra concentrada, na sua completa diversidade, a totalidade da representatividade da vontade popular institucional e juridicamente operante" (D19).

A2. Hierarquização de prioridades (priorização da prevenção da infertilidade e de opções "sociais" ou do financiamento de tratamentos de reprodução assistida; priorização do diagnóstico de infertilidade face a "escolhas individuais" das mulheres).

[A2.a] "A decisão livre do casal provém da convergência e da harmonização de duas decisões livres, em que tem particular relevância a decisão da mulher, visto ser ela o primeiro sujeito do processo reprodutivo e a principal afetada pelas técnicas de reprodução medicamente assistida. As mulheres têm o direito e a responsabilidade de decidirem, por si próprias e de acordo com as suas circunstâncias, as opções reprodutivas que querem seguir" (D1).

[A2.b] "O acesso à aplicação das técnicas de procriação medicamente assistida a todas as mulheres [independentemente do estatuto marital e da orientação sexual] (...) é suscetível de (...) gerar desigualdades entre situações que dependem de diagnóstico clínico e situações de acesso por escolha individual. (...) Quando tenham de ser considerados os recursos específicos de saúde a alocar, impõe-se a definição de prioridades assentes em critérios explícitos nos quais a condição de doença deve prevalecer sobre as opções individuais" (D21).

[A2.c] "A prevenção da infertilidade é (...) preferível às tentativas da sua superação. (...) Urge investigar (...) causas evitáveis de infertilidade e desenvolver (...) programas de prevenção, de educação para a saúde e para a sexualidade e serviços de aconselhamento da população. As opções sociais (adoção, iniciativas assistenciais, atitude de assumir voluntariamente a condição de infértil) poderão constituir, para muitos casais, a melhor forma de superar a ausência de filhos" (D1).

[A2.d] "Alguns admitem que os recursos gastos em esterilidade pudessem ser minorados a médio prazo se o Estado investisse também noutras políticas de apoio à parentalidade, conforme o modelo sueco. (...) O CNECV recomenda (...) que sejam promovidas medidas sociais que invertam a concretização cada vez mais tardia da parentalidade (...) [e] a promoção de medidas que incentivem a adoção, bem como a simplificação dos respectivos processos" (D10).

[A2.e] "A taxa de sucesso da adoção é muito superior à da procriação medicamente assistida... (...) [Aconselhamento] Não deveria ser feito em centros de procriação medicamente assistida mas estar incluído nos cuidados primários da saúde" (D4).

[A2.f] "Alguns interrogam-se se será eticamente aceitável (...) impor limitações ao financiamento da procriação medicamente assistida, num contexto de envelhecimento populacional e em que se financiam cuidados diametralmente opostos (IVG), sem taxa moderadora mesmo nos casos recorrentes" (D10).

(continua) 


\section{A3. Seleção de receptores (estatuto marital, orientação sexual e idade).}

[A3.a] “O princípio da não instrumentalização da pessoa humana (...) leva-nos, assim, a concluir que essas técnicas (...) devem aplicar-se exclusivamente a casais heterossexuais com garantias de estabilidade (legalmente constituídos ou não) e de condições adequadas para o completo e harmônico desenvolvimento do nascituro" (D1).

[A3.b] "Indica-se, como condição a ter particularmente em conta para assegurar o desenvolvimento integral da criança, o direito a beneficiar da estrutura familiar, biparental, da filiação" (D4).

[A3.c] "De notar que o alargamento do acesso às técnicas [a todas as mulheres] traz consigo um empobrecimento da matriz cultural da família e a desvalorização do impacto que tem sobre o desenvolvimento da criança" (D17).

[A3.d] “Com o alargamento do acesso [a todas as mulheres] (...) é premente assegurar o princípio da igualdade de tratamento (...) favorecendo-se a equidade no acesso (...) sem exclusão, assegurando-se uma prestação de serviços adequada, segura e não discriminatória" (D20).

[A3.e] "Em regra, a partir de certa idade os pais não estão em condições de proporcionar aos filhos os apoios de que eles necessitam (...). Acresce que para lá dos 40 anos é pequena a probabilidade de sucesso da procriação medicamente assistida. Face aos interesses da criança a nascer e também em cumprimento dos (...) direitos dos beneficiários a não ser submetidos a técnicas que não ofereçam razoáveis probabilidades de êxito, entende-se ser de indicar o limite da idade a partir do qual não é permitida a procriação medicamente assistida (é o que, quanto à mulher, sucede na Holanda, Hungria e Islândia). (...) Num documento da Organização Mundial da Saúde recomenda-se incisivamente que a idade limite seja, na mulher, de 40 anos" (D4).

[A3.f] "Limite etário no acesso às técnicas de procriação medicamente assistida (...) é uma matéria sensível (...) essencial para impedir usos abusivos e despropositados destas técnicas (...) e também para evitar que nos centros de procriação medicamente assistida, públicos ou privados, possam ser consideradas distintas idades limite na seleção de casais e das mulheres elegíveis (...) o que constituiria uma inequívoca violação do princípio da igualdade - aliás princípio da proibição da desigualdade justificada - consagrado (...) [na] Constituição da República (...), Declaração Universal dos Direitos Humanos (...), Carta dos Direitos Fundamentais da União Europeia (...); para proteger os membros mais desprotegidos da comunidade (...) contra a criação de falsas esperanças e infundamentadas expectativas. (...) A imposição de limites [etários] (...) pode ser determinada quando colide com (...) saúde física e mental das mulheres envolvidas nos tratamentos (...) ou procedimentos (...) e [com] o superior interesse das crianças que venham a nascer (...). Só são elegíveis as mulheres (...) [cuja idade] não ultrapasse os 49 anos e 365 dias" (D24).

[A3.g] "Só pode adotar plenamente quem não tiver mais de 60 anos (...) [devido ao] interesse superior da criança em crescer (...) física, mental, moral, espiritual e socialmente de forma saudável e emocionalmente equilibrada (...). É conveniente que nunca se esqueça que numa família emocionalmente equilibrada o sentimento de perda (...) pode ser devastador. (...) É eticamente justificado e socialmente legítimo estabelecer que (...) só são elegíveis os casais que (...) o elemento masculino tenha uma idade que não ultrapasse os 60 anos" (D25).

CNECV: Conselho Nacional de Ética para as Ciências da Vida; CNPMA: Conselho Nacional de Procriação Medicamente Assistida. Fonte: Documentos emitidos pelo CNECV 33 e pelo CNPMA 34 sobre as implicações sociais e éticas da doação de gametas.

[A2.f]. A decisão da mulher foi considerada uma responsabilidade individual por nela se concentrar a maioria dos procedimentos [A2.a], mas foi questionada a valorização das preferências e "escolhas individuais” femininas nas situações de acesso a técnicas de reprodução assistida não relacionadas com a existência de um diagnóstico clínico [A2.b].

A essa hierarquização subjaz, implicitamente, o estabelecimento de prioridades com base no estatuto marital e na orientação sexual de receptores, critérios onipresentes no debate social e ético por via quer do princípio da não instrumentalização da pessoa humana [A3.a] e do direito das crianças a um desenvolvimento integral [A3.b, A3.c], quer do princípio da igualdade de tratamento e não discriminação [A3.d]. Os interesses das crianças em crescer "de forma saudável e emocionalmente equilibrada”, assim como o "princípio da proibição da desigualdade justificada” entre centros de reprodução assistida públicos e privados e o direito dos receptores "a não ser submetidos a técnicas que não ofereçam razoáveis probabilidades de êxito”, sustentaram, ainda, a definição de uma idade máxima para acesso à reprodução assistida: 40 anos [A3.e] até o final de 2017 e 50 anos a partir de 2018 para as mulheres [A3.f], e 60 anos de idade para os homens desde 2013 [A3.g], com base em regulamentações de outros países e em orientações de entidades internacionais. 


\section{Regimes de anonimato e de compensação de doadores}

No Quadro 2 encontram-se os principais excertos ilustrativos do debate no âmbito dos regimes de anonimato e de compensação de doadores. O princípio da liberdade e autonomia de doadores e receptores justificou a opção pela doação de gametas anônima, mas nos documentos analisados também se ponderaram os desafios associados a este regime. Mencionou-se a eventual instrumentalização de doadores e a negação da respectiva "auto-realização procriativa na linha da liberdade ética” [B1.a], assim como a fragilização do direito à identidade genética das pessoas nascidas por intermédio da doação de gametas nos casos em que é vedado o acesso ao conhecimento "da identidade dos progenitores" [B1.b]. Apelou-se, por um lado, à consagração legal de mecanismos que proporcionem informação sobre a "origem parental" quando esta for exigida por quem nasceu por intermédio da doação de gametas [B1.c] e, por outro, à realização de estudos sobre os processos de revelação [B1.d] e as consequências para a saúde e bem-estar de todos os envolvidos [B1.e]. Questionou-se, ainda, a hipotética associação entre a doação de gametas não anônima e a escassez de doadores com base na experiência sueca [B1.f], alegando-se a ausência de evidência científica e o fato de, atualmente, o anonimato não se traduzir num número suficiente de doadores em Portugal [B1.g].

A discussão em torno da compensação a atribuir a doadores de gametas foi dominada pelo reconhecimento da necessidade de estabelecer limites justos e proporcionados por meio de uma regulamentação nacional e de proceder à respetiva fiscalização [B2.a], assim como pelo apelo à transparência na promoção e publicidade da doação [B2.b]. Esses elementos serão fundamentais para alcançar um triplo objetivo enunciado em diversas normas e recomendações europeias: realçar o caráter voluntário, altruísta e desinteressado da doação [B2.b]; promover a uniformização dos princípios éticos aplicados à doação de gametas [B2.c]; e proteger os envolvidos de uma eventual exploração [B2.d] e comercialização [B2.e].

\section{Responsabilidades dos profissionais envolvidos na doação de gametas}

No Quadro 3 estão os extratos ilustrativos do debate social e ético em torno das responsabilidades dos profissionais envolvidos na doação de gametas. Foi referido o seu dever de informar receptores e doadores de gametas sobre aspetos técnico-científicos, psicológicos, sociais, econômicos, legais e éticos, respeitando o princípio da autonomia [C1.a], e de disseminar publicamente os resultados das atividades dos centros de reprodução assistida [C1.b]. Mencionou-se, ainda, a necessidade de salvaguardar a liberdade e autonomia dos profissionais de saúde, salvaguardando o respectivo direito à objeção de consciência [C2.a].

\section{Discussão}

Os tópicos referidos nos documentos emitidos pelo CNPMA e pelo CNECV sobre as implicações sociais e éticas da doação de gametas em Portugal gravitaram, sobretudo, em torno da acessibilidade e dos regimes de anonimato e de compensação de doadores. As responsabilidades dos profissionais que trabalham na área da doação de gametas também foram mencionadas, embora com menor frequência. Observaram-se posicionamentos heterogêneos quanto à governança da doação de gametas, refletindo dois aspetos. Em primeiro lugar, espaços de tensão entre princípios éticos, cuja aplicação variou de acordo com o contexto sociopolítico e técnico, e os atores a quem foi conferida primazia na ponderação entre direitos e interesses eventualmente contraditórios (por exemplo, o direito à identidade genética de pessoas concebidas por intermédio da doação de gametas, e o respeito pela autonomia e salvaguarda da confidencialidade de receptores e doadores). Em segundo lugar, entendimentos distintos sobre os atores que devem ser envolvidos nas reflexões éticas sobre a doação de gametas (se apenas as entidades reguladoras tuteladas pelo governo ou, também, stakeholders e demais representantes da sociedade civil). Subjacente a essa diversidade de posições, verificou-se o acionamento de dois argumentos transversais à produção ético-argumentativa: a escassez de evidência científica, particularmente sobre os processos de revelação e as consequências da doação de gametas para a saúde e 


\section{Quadro 2}

Extratos sobre os regimes de anonimato e de compensação de doadores.

B1. Desafios associados ao anonimato (instrumentalização de doadores; fragilização do direito à identidade genética; necessidade de estudos sobre a revelação, as consequências para a saúde e bem-estar dos envolvidos e o impacto no número de doadores).

[B1.a] "A sua instrumentalização, reduzindo-o [doador] a um produtor de gametas. A negação da sua auto-realização procriativa na linha da liberdade ética, transmitindo vida desresponsabilizado de um projeto parental e de um contexto familiar" (D1).

[B1.b] “O conhecimento da identidade dos progenitores faz parte da historicidade pessoal e, portanto, da identidade própria e singular, pelo que a ninguém deve ser negado o acesso a esse conhecimento (...). Este direito (...) é reconhecido na Alemanha, Áustria, Suécia e Suiça (pelo menos). E no preâmbulo da resolução sobre fertilização in vitro e in vivo do Parlamento Europeu, de 1989, inclui-se (...) o 'direito a uma identidade genética" (D4).

[B1.c] "Seria prudencial contemplar uma proposta de regulamentação (...) sobre a questão da confidencialidade/acesso aos dados por parte da pessoa nascida com aplicação das técnicas de procriação medicamente assistida. (...) Devem estar consagrados em lei mecanismos para proporcionar informação sobre a origem parental quando for exigida em tempo próprio por quem nascer por aplicação deste tipo de técnicas" (D21).

[B1.d] "Não se conhecem entre nós estudos sobre (...) a questão do direito da criança à respectiva identidade e da preocupação dos pais com os futuros interesses dos futuros filhos, designadamente as consequências (...) que o secretismo (...) sobre a respectiva origem (...) possa ter nalguns dos seus filhos. (...) Quantas crianças (...) querem conhecer, quantas podem conhecer e quantas conhecem os pais genéticos? (...). Deve ou não revelar-se a uma criança as suas origens biológicas (genéticas elou gestacionais)? Interessa ou não à criança saber a origem dos gametas (...)? O que se sabe entre nós sobre o bem-estar a longo termo da criança concebida com recurso a doação de gametas?" (D10).

[B1.e] "Há que ter em conta a possibilidade de ocorrência, a médio ou longo prazo, de consequências gravosas para o casal elou para a pessoa nascida; só estudos sistemáticos e fiáveis permitirão tirar conclusões a tal respeito" (D4).

[B1.f] "E não colhe o argumento de que [o não anonimato] (...) levará à inexistência de dadores de sémen. (...) A experiência sueca demonstra o contrário" (D4).

[B1.g] "Está por comprovar que a doação de gametas não anônima diminua drasticamente o número de dadores de gametas em Portugal. (...) De resto, sob o atual anonimato, o número de dadores é insuficiente - daí continuar a recorrer-se à importação de gametas no estrangeiro" (D10).

B2. Compensação atribuída a doadores (estabelecimento de limites, transparência, fiscalização e uniformização de princípios éticos).

[B2.a] “Uma Resolução do Parlamento Europeu [de 2012] (...) considera vital que os Estados-Membros definam claramente as condições em que pode ser concedida uma compensação financeira justa e proporcionada, (...) mais referindo (...) que as compensações devem ser transparentes e regularmente fiscalizadas" (D13).

[B2.b] "A promoção e publicidade da dádiva devem realizar-se sempre em termos genéricos, obedecendo aos princípios da transparência, rigor científico, fidedignidade e inteligibilidade da informação, sem procurar benefícios para pessoas concretas, e evidenciando o seu carácter voluntário, altruísta e desinteressado" (D9).

[B2.c] “O valor altruísta e solidário da dádiva de tecidos e células fica melhor salvaguardado através da uniformização dos requisitos técnicos (...). É necessário, também do ponto de vista ético, promover a uniformização e coerência dos princípios [respeito pela dignidade, autonomia e integridade da pessoa, salvaguardando-se a sua saúde, segurança e privacidade] que se aplicam a situações idênticas" (D22).

[B2.d] "As normas e recomendações para a atribuição de compensações aos dadores, em vigor na maioria dos países da União Europeia (...) postulam: (...) a competência dos Estados-Membros para autorizar e fixar os montantes compensatórios; a necessidade de uma rigorosa regulamentação, a fim de proteger os dadores e os recetores/beneficiários e de lutar contra toda e qualquer forma de exploração humana" (D8).

[B2.e] "A partir de que montante uma compensação é um pagamento que objetivamente transforma a "doação" numa venda e comercialização de parte do corpo, consensualmente criticável do ponto de vista ético? (...) A doação de gametas é voluntária, de carácter benévolo, e não remunerada (...)" (D10).

CNECV: Conselho Nacional de Ética para as Ciências da Vida; CNPMA: Conselho Nacional de Procriação Medicamente Assistida. Fonte: Documentos emitidos pelo CNECV 33 e pelo CNPMA 34 sobre as implicações sociais e éticas da doação de gametas.

bem-estar de todos os envolvidos; e a utilização de experiências de outros países e de regulamentações e/ou entidades internacionais.

Em Portugal, o alargamento, em 2016, do acesso à doação de gametas a mulheres independentemente da existência de um diagnóstico de infertilidade, do estado civil ou orientação sexual, alinha com as atuais recomendações da ESHRE 36 e da ASRM 37, que consideram esta norma eticamente aceitável com base no respeito pelos princípios da autonomia, beneficência, não-maleficência e 


\section{Quadro 3}

Extratos sobre as responsabilidades dos profissionais envolvidos na doação de gametas.

C1. Informar (receptores e doadores; aspetos técnico-científicos, psicossociais, econômicos, éticos e legais; disseminar resultados das atividades dos centros de reprodução assistida).

[C1.a] "Os beneficiários das técnicas de procriação medicamente assistida devem ser claramente informados acerca da natureza técnico-científica do processo, incluindo a descrição das intervenções a que serão sujeitos e seus potenciais benefícios e riscos, designadamente os que podem afetar os interesses da criança a nascer. (...) A informação prestada deverá igualmente incidir sobre os seguintes aspectos: psicológicos (...), sociais (...), legais (...), econômicos (...); e éticos (...). Também o dador de gametas deverá ser claramente informado acerca da natureza e implicações do ato a que se propõe, no cumprimento da regra do consentimento informado, implicada no princípio da autonomia" (D6).

[C1.b] "O CNECV recomenda (...) a divulgação pública das taxas de eficácia (que devem ser expressas pela taxa de gravidez clínica por ovócitos colhidos e pela taxa de recém-nascidos saudáveis por ovócitos colhidos, com a indicação da percentagem de gemelaridade, conforme recomendado pelas sociedades europeias de genética e de medicina da reprodução e embriologia) dos diferentes centros (...), corrigidas por grupos etários e diferentes critérios de seleção" (D10).

C2. Objeção de consciência.

[C2.a] "Deverá ser garantido aos profissionais de saúde o direito à objeção de consciência relativamente à execução das técnicas de procriação medicamente assistida, consignado pelo princípio da autonomia" (D6).

CNECV: Conselho Nacional de Ética para as Ciências da Vida; CNPMA: Conselho Nacional de Procriação Medicamente Assistida.

Fonte: Documentos emitidos pelo CNECV 33 e pelo CNPMA 34 sobre as implicações sociais e éticas da doação de gametas.

justiça. Já a discussão em torno da definição da idade a partir da qual deve ser limitado o acesso à doação de gametas não reúne consenso. Recorrendo ao exemplo de outros países europeus e a recomendações internacionais, Portugal estendeu, em 2017, a idade máxima das receptoras dos 40 anos para os 49 anos e 365 dias, ao mesmo tempo em que reestabeleceu o limite de idade para os elementos masculinos de casais heterossexuais - 60 anos, fixado em 2013 e suspenso em 2016. Se a ASRM pondera o acesso à doação de ovócitos por parte de mulheres até aos 54 anos, mediante avaliação médica, psicológica e social 38, a ESHRE aponta para os 50 anos 31, ao passo que a idade masculina só é abordada no contexto da doação de gametas intrafamiliar 39,40. Em todas essas propostas alega-se, em simultâneo, a necessidade do apoio e acompanhamento dos pais para garantir o desenvolvimento integral das crianças, e a proteção da saúde das mulheres ao minimizar a probabilidade de ocorrência de riscos durante a gravidez e da criação de expectativas infundadas quanto ao sucesso dos tratamentos.

Na discussão em torno da acessibilidade à doação de gametas, em particular no que diz respeito à seleção de receptores e à hierarquização de prioridades, vislumbrou-se uma política de reprodução preferencialmente dirigida às mulheres 41 , em que se ponderou a contribuição das técnicas de reprodução assistida para inverter o atual envelhecimento demográfico face ao investimento político em programas de prevenção, aconselhamento e de educação para a saúde da população. Para responder a esses (e outros) desafios com base em evidência científica, nos documentos analisados apelou-se ao desenvolvimento de estudos para gerar informações sobre questões técnicas, sociais e éticas associadas à doação de gametas e à promoção de uma reflexão coletiva, diferindo, contudo, quanto à forma de fazer: o CNECV defendeu uma reflexão envolvendo um amplo número de cidadãos no alcance de soluções para os objetivos comuns, e o CNPMA entendeu que a reflexão deverá ficar a cargo do governo, e das instituições sob sua tutela, na condição de legítimos representantes da "vontade popular". Nos documentos emitidos pela ESHRE e pela ASRM defende-se a inclusão, em termos éticos, dos interesses de todos os stakeholders, ou seja, doadores, receptores, pessoas concebidas pela doação de gametas e profissionais de saúde 11,24, assim como a consideração de eventuais danos para a "sociedade como um todo" 36. No entanto, as perspectivas da população em geral raramente são incluídas nos estudos desenvolvidos sobre as implicações sociais e éticas da doação de gametas 42. Esses aspectos revelam a necessidade de promover práticas efetivas de participação da comunidade 43 e de adotar 
metodologias inovadoras que potenciem a participação de todos os stakeholders com total respeito por eventuais regimes de anonimato da doação de gametas 44 .

Em nível nacional salientou-se, ainda, a importância de uniformizar os princípios éticos aplicados à doação de gametas, sobretudo no contexto do intercâmbio transfronteiriço de células reprodutivas. Também a ASRM e a ESHRE alertaram para as implicações sociais e éticas da circulação de gametas entre países, mencionando a possibilidade de ocorrência de danos (físicos, psicossociais e econômicos) quer em doadores 13 , quer nos receptores 45 , assim como as dificuldades de acesso à informação sobre o processo de doação por parte de pessoas concebidas com gametas importados de outros países 13. Para além da harmonização de princípios éticos e de procedimentos técnicos, importa incluir no debate de todos os países a discussão em torno de dois tópicos centrais. Em primeiro lugar, o desenvolvimento e implementação de sistemas de registo reprodutivo 46, para receptores e doadores, capazes de gerar dados fidedignos e de proporcionar a monitorização eficaz da utilização nacional e transfronteiriça das técnicas de reprodução assistida, mas que também contribua para eliminar lacunas de informação quanto às implicações sociais e éticas da doação de gametas. Em segundo lugar, quais os limites da informação de saúde que deve ou não ser disponibilizada a doadores, a receptores e pessoas concebidas com recurso de doação de gametas, e em que circunstâncias, particularmente no âmbito da realização de rastreios genéticos 11 .

Perante a diversidade de políticas, regulamentações e práticas em nível global quanto ao anonimato ou à identificação de doadores reconhecida nos documentos analisados, a ESHRE propôs, em 2002, o double track (uma via dupla onde doadores e receptores poderão exercer, simultaneamente, a opção pela doação anônima ou não anônima) como a solução que melhor equilibra os direitos e interesses de doadores (direito à privacidade), receptores (direito à privacidade e autonomia) e pessoas nascidas por intermédio da doação de gametas (direito a conhecer as suas origens genéticas) 23, a qual também consideraria o direito de todos os envolvidos a serem esquecidos 47 . Importa, em qualquer das alternativas, salvaguardar a possibilidade e clarificar em que circunstâncias pode ocorrer o acesso à informação sobre o processo de doação, incluindo a informação disponível sobre os doadores 8,40,48,49.

A possibilidade de uma via dupla não foi mencionada nos documentos analisados, assim como não foi discutida a doação de gametas por parte de familiares e/ou conhecidos, aspetos já contemplados pela ESHRE 39 e pela ASRM 40. Uma vez que o debate focou nos desafios levantados pelo anonimato e na sua relação com o número de doadores, foi omitida a discussão sobre as implicações sociais e éticas de uma doação identificável, não obstante a tendência para a abolição do anonimato registada em diversos países europeus 50, incluindo Portugal 21. Desse modo, o debate nos documentos emitidos pelas organizações de ética portuguesas poderá ter contribuído para reforçar a ideia de que as relações biogenéticas constituem um elemento fundamental na identidade dos indivíduos 51,52. Também não foi discutida a possibilidade dos doadores terem acesso à informação sobre os resultados da sua doação e de escolherem as características dos receptores dos seus gametas, como a idade, nível de escolaridade, estado civil ou estado de saúde, conforme discutido pela ASRM 24. Esteve ainda ausente do debate social e ético em Portugal uma reflexão sobre eventuais quebras no anonimato da doação pela utilização de testes genéticos diretos no consumidor 8,53. A partilha dos resultados desses testes na internet e, particularmente, nas redes sociais, tem proporcionado o estabelecimento de ligações entre pessoas concebidas por intermédio de gametas dos mesmos doadores 54 .

A necessidade de transparência e de estabelecer limites ao valor da compensação atribuída a doadores, assim como a respetiva fiscalização para assegurar o caráter altruísta da doação e proteger os envolvidos de uma eventual exploração e comercialização, foram tópicos também abordados pela ESHRE e pela ASRM, quer na doação para fins reprodutivos 13,26,49, quer na doação para fins de pesquisa científica 10 , sendo especialmente relevante na doação de ovócitos 55 . Já as implicações sociais e éticas da variabilidade do valor monetário associado à compensação pela doação de gametas entre países 56 não foram objeto de reflexão nos documentos analisados.

O debate nacional em torno das responsabilidades profissionais assemelhou-se à discussão patrocinada pela ESHRE 23 e pela ASRM 24 ao referir o dever de prestar informações sobre aspetos técnicocientíficos, psicossociais, econômicos e legais associados à doação de gametas. Porém, não se discutiu a possibilidade de doadores se manifestarem em relação ao destino dos embriões criopreservados criados a partir dos seus gametas, em particular no consentimento quanto à respectiva doação para fins de pesquisa científica, como contemplado pela ASMR ${ }^{10}$. No que concerne o direito dos profis- 
sionais à objeção de consciência, a ESHRE também reconhece que estes podem se recusar a integrar a equipe em casos "atípicos" (non-standard cases), mas alerta para a necessidade de evitar situações de discriminação e preconceito 36 .

A análise exclusiva de documentos emitidos pelo CNECV e pelo CNPMA circunscreve os resultados obtidos quanto ao debate social e ético em Portugal, apesar destes serem os dois principais órgãos independentes de âmbito nacional que se pronunciam sobre as questões éticas e sociais associadas às técnicas de reprodução assistida, no geral, e à doação de gametas, em particular. Também a exclusão de documentos que apenas abordassem aspetos relacionados com a qualidade e a segurança de procedimentos limitou a discussão ética sobre as boas práticas profissionais face à ocorrência de erros. No entanto, replicar a metodologia utilizada neste artigo em outros países possibilita o mapeamento e análise das similitudes e diferenças entre os temas abordados em nível nacional e os tópicos abordados no nível internacional, o que constitui uma valiosa estratégia para antecipar potenciais desafios, riscos, incertezas e controvérsias, contribuindo para a formulação de políticas de saúde e de ciência no âmbito da medicina reprodutiva mais adequadas às necessidades sociais e científicas.

\section{Conclusão}

Foram identificados os principais tópicos referidos em 25 documentos emitidos pelo CNPMA e pelo CNECV sobre as implicações sociais e éticas da doação de gametas em Portugal, entre 1993 e 2017 : acessibilidade; regimes de anonimato e de compensação de doadores; e responsabilidades dos profissionais envolvidos na doação de gametas. Observaram-se posicionamentos heterogêneos e espaços de tensão entre direitos e princípios éticos, mas foram identificadas regularidades na produção éticoargumentativa: a escassez de evidência científica e a utilização de experiências de outros países e de orientações referidas em regulamentações e/ou entidades internacionais.

Considerando as discussões em curso nas sociedades que são líderes mundiais na área da medicina reprodutiva, há espaço para expandir o debate social e ético no que concerne aos tópicos abordados e aos stakeholders envolvidos. Importa promover a pesquisa em torno das implicações sociais e éticas da doação de gametas em diversos contextos, incluindo as perspectivas de todos os envolvidos, para contribuir para a avaliação das tecnologias de reprodução assistida e para o desenvolvimento de políticas de saúde baseadas na evidência 57 .

A governança da doação de gametas beneficiará de um modelo assente na coprodução 29,30, em que diferentes stakeholders (incluindo elementos e entidades da sociedade civil e pessoas excluídas do acesso às técnicas) participem numa discussão plural e inclusiva 26 sobre as implicações atuais e futuras associadas à doação de gametas, e sobre a reconfiguração dos direitos reprodutivos e sexuais 58 , assim como dos direitos e dos deveres de cidadania decorrentes do acesso e utilização de técnicas de reprodução assistida heterólogas 3,51,59.

Essas medidas podem promover a pesquisa e inovação socialmente responsáveis em medicina reprodutiva, assim como a definição e implementação de políticas e cuidados de saúde centrados nas pessoas. Essas são basilares para a melhoria da qualidade dos serviços, particularmente no âmbito da prestação de informação a atuais e futuros doadores e receptores sobre desafios, riscos, incertezas e controvérsias associados à doação de gametas. Esses aspectos reforçam, também, o importante papel desempenhado pelos profissionais de saúde envolvidos na doação de gametas e a necessidade de estarem informados sobre as principais implicações sociais e éticas discutidas em níveis nacional e internacional. 


\section{Colaboradores}

S. Pinto da Silva e S. Silva contribuíram na concepção e projeto; aquisição dos dados; análise e interpretação dos dados; redação do artigo; aprovação da versão final do manuscrito e responsabilidade por todos os aspectos do trabalho na garantia da integralidade de qualquer parte da obra. C. De Freitas, C. Samorinha e H. Machado contribuíram na análise e interpretação dos dados; revisão crítica do artigo; aprovação da versão final do manuscrito e responsabilidade por todos os aspectos do trabalho na garantia da integralidade de qualquer parte da obra. I. Baía contribuiu na aquisição dos dados; análise e interpretação dos dados; revisão crítica do artigo; aprovação da versão final do manuscrito e responsabilidade por todos os aspectos do trabalho na garantia da integralidade de qualquer parte da obra.

\section{Informações adicionais}

ORCID: Sandra Pinto da Silva (0000-0003-47185957); Cláudia De Freitas (0000-0002-1828-8642); Inês Baía (0000-0002-8621-6288); Catarina Samorinha (0000-0002-6662-0347); Helena Machado (0000-0001-8554-7619); Susana Silva (0000-00021335-8648).

\section{Agradecimentos}

À Fundação para a Ciência e a Tecnologia (FCT) por intermédio dos Programas COMPETE 2020, POCH e Portugal 2020, e à União Europeia, por meio do FEDER e do FSE, no âmbito do projeto POCH-01-0145-FEDER-016762 (Ref. FCT PTDC/IVC-ESCT/6294/2014), da Unidade de Investigação em Epidemiologia - ISPUP (EPIUnit - POCH-01-0145-FEDER-006862; Ref. FCT UID/DTP/04750/2013), das bolsas de doutorado SFRH/BD/122603/2016 (S. Pinto da Silva) e SFRH/ BD/111686/2015(I. Baía), do DL57/2016/CP1336/ CT0001 (C. De Freitas), e do contrato Investigador FCT IF/01674/2015 (S. Silva).

\section{Referências}

1. Barretto VP, Lauxen ECU. O marco inicial da vida humana: perspectivas ético-jurídicas no contexto dos avanços biotecnológicos. Cad Saúde Pública 2017; 33:e00071816.

2. Harper JC, Aittomäki K, Borry P, Cornel MC, de Wert G, Dondorp W, et al. Recent developments in genetics and medically assisted reproduction: from research to clinical applications. Eur J Hum Genet 2018; 26:12-33.

3. Silva S, Samorinha C, Baía I, Pinto da Silva S, De Freitas C. Genes, cidadania e participação na doação de gâmetas. In: Machado H, editor. Genética e cidadania. Porto: Edições Afrontamento; 2017. p. 221-40.

4. Bracewell-Milnes T, Saso S, Bora S, Ismail AM, Al-Memar M, Hamed AH, et al. Investigating psychosocial attitudes, motivations and experiences of oocyte donors, recipients and egg sharers: a systematic review. Hum Reprod Update 2016; 22:450-65.

5. Daniels K. Anonymity and openness and the recruitment of gamete donors. Part I: semen donors. Hum Fertil 2007; 10:151-8.

6. Daniels K. Anonymity and openness and the recruitment of gamete donors. Part 2: oocyte donors. Hum Fertil 2007; 10:223-31.

7. Indekeu A, Dierickx K, Schotsmans P, Daniels KR, Rober P, D'Hooghe T. Factors contributing to parental decision-making in disclosing donor conception: a systematic review. Hum Reprod Update 2013; 19:714-33.

8. Zadeh S. Disclosure of donor conception in the era of non-anonymity: safeguarding and promoting the interests of donor-conceived individuals? Hum Reprod 2016; 31:2416-20.

9. Ethics Committee of the American Society for Reproductive Medicine. Donating embryos for human embryonic stem cell (hESC) research: a committee opinion. Fertil Steril 2013; 100:935-9.

10. Ethics Committee of the American Society for Reproductive Medicine. Informed consent and the use of gametes and embryos for research: a committee opinion. Fertil Steril 2014; 101:332-5.

11. Dondorp W, De Wert G, Pennings G, Shenfield F, Devroey P, Tarlatzis B, et al. ESHRE Task Force on Ethics and Law 21: genetic screening of gamete donors: ethical issues. Hum Reprod 2014; 29:1353-9.

12. Le Lannou D. Quelle strategie pour ameliorer le recrutement des donneurs de gamete. Gynecol Obstet Fertil 2013; 41:711-4.

13. Ethics Committee of the American Society for Reproductive Medicine. Cross-border reproductive care: an Ethics Committee opinion. Fertil Steril 2016; 106:1627-33.

14. Faircloth C, Gurtin Z. Introduction - making parents: reproductive technologies and parenting culture across borders. Sociol Res Online $2017 ; 22: 1-5$.

15. Governo de Portugal. Lei no 32/2006 de 26 de julho. Procriação medicamente assistida. Diário da República 2006; 1a Série, no 10. p. 5245-50. 
16. Silva S, Machado H. A governação dos pacientes adequados no acesso à Procriação Medicamente Assistida em Portugal. Sociologia, Problemas e Práticas 2010; 62:81-96.

17. Governo de Portugal. Lei no 17/2016, de 20 de junho. Diário da República 2016; 1a Série, no 116; p. 1903-4.

18. Conselho Federal de Medicina. Resolução CFM no 2.013/2013. Adota as normas éticas para a utilização das técnicas de reprodução assistida, anexas à presente resolução, como dispositivo deontológico a ser seguido pelos médicos e revoga a Resolução CFM no 1.957/10. Diário Oficial da União 2013; 9 mai.

19. Governo de Portugal. Assembleia da República, Série II. Diário da República 2017; p. 1098-9.

20. Serviço Nacional de Saúde. Portugal: Governo da República Portuguesa. Banco público de gâmetas. https://www.sns.gov.pt/cidadao/ban co-publico-de-gametas-2/ (acessado em 12/ Jun/2018).

21. Tribunal Constitucional. Acórdão do Tribunal Constitucional no 225/2018, Processo no 95/17. Diário da República 2018, 1a Série, no 87; p. 1885-979.

22. Conselho Federal de Medicina. Resolução CFM no 2.168/2017. Diário Oficial da União 2017; 10 nov.

23. ESHRE Task Force on Ethics and Law. III. Gamete and embryo donation. Hum Reprod 2002; 17:1407-8.

24. Ethics Committee of the American Society for Reproductive Medicine. Interests, obligations, and rights in gamete donation: a committee opinion. Fertil Steril 2014; 102:675-81.

25. Silva S. Consentir incertezas: o consentimento informado e a (des)regulação das tecnologias de reprodução assistida. Cad Saúde Pública 2008; 24:525-34.

26. De Freitas C, Martin G. Inclusive public participation in health: policy, practice and theoretical contributions to promote the involvement of marginalised groups in healthcare. Soc Sci Med 2015; 135:31-9.

27. Ferreira PL, Raposo V. A governação em saúde e a utilização de indicadores de satisfação. Rev Port Clín Geral 2006; 22:285-96.

28. Kickbusch I, Gleicher D. Governance for health in the 21st century. Copenhagen: WHO Regional Office for Europe; 2012.

29. World Health Organization. Health 2020: a European policy framework and strategy for the 21 st century. Copenhagen: WHO Regional Office for Europe; 2013.

30. World Health Organization. WHO global strategy on integrated people-centred health services 2016-2026: placing people and communities at the centre of health services. Geneva: World Health Organization; 2015.

31. European Society of Human Reproduction and Embryology. Statements by the ESHRE Task Force on Ethics and Law. https://www. eshre.eu/Specialty-groups/Special-InterestGroups/Ethics-and-Law/Documents-of-theTask-Force-Ethics-Law.aspx (acessado em 12/ Jun/2018).
32. American Society for Reproductive Medicine. Ethics Committee Opinions and Webinars. http://www.asrm.org/news-and-publications/ ethics-committee-documents/ (acessado em 12/Jun/2018).

33. Conselho Nacional de Ética para as Ciências da Vida. Pareceres, 2018. http://www.cnecv. pt/pareceres.php (acessado em 12/Jun/2018).

34. Conselho Nacional de Procriação Medicamente Assistida. Documentação. http://www.cnp ma.org.pt/cnpma_documentacao.aspx (acessado em 12/Jun/2018).

35. Braun V, Clarke V. Using thematic analysis in psychology. Qual Res Psychol 2006; 3:77-101.

36. De Wert G, Dondorp W, Shenfield F, Barri P, Devroey P, Diedrich K, et al. ESHRE Task Force on Ethics and Law 23: Medically assisted reproduction in singles, lesbian and gay couples, and transsexual people. Hum Reprod 2014; 29:1859-65.

37. Ethics Committee of the American Society for Reproductive Medicine. Access to fertility treatment by gays, lesbians, and unmarried persons: a committee opinion. Fertil Steril 2013; 100:1524-7.

38. Ethics Committee of the American Society for Reproductive Medicine. Oocyte or embryo donation to women of advanced reproductive age: an Ethics Committee opinion. Fertil Steril 2016; 106:e3-e7.

39. ESHRE Task Force on Ethics and Law. Intrafamilial medically assisted reproduction. Hum Reprod 2011; 26:504-9.

40. Ethics Committee of the American Society for Reproductive Medicine. Using family members as gamete donors or gestational carriers. Fertil Steril 2017; 107:1136-42.

41. Silva S. Procriação medicamente assistida: práticas e desafios. Lisboa: Imprensa de Ciências Sociais; 2014.

42. Hudson N, Culley L, Rapport F, Johnson M, Bharadwaj A. "Public" perceptions of gamete donation: a research review. Public Underst Sci 2009; 18:61-77.

43. Matos AR, Serapioni M. O desafio da participação cidadã nos sistemas de saúde do Sul da Europa: uma revisão da literatura. Cad Saúde Pública 2017; 33:e00066716.

44. De Freitas C. Public and patient participation in health policy, care and research. Porto Biomedical Journal 2017; 2:31-2.

45. Pennings G, de Wert G, Shenfield F, Cohen J, Tarlatzis B, Devroey P. ESHRE Task Force on Ethics and Law 15: cross-border reproductive care. Hum Reprod 2008; 23:2182-4.

46. De Geyter C, Wyns C, Mocanu E, de Mouzon J, Calhaz-Jorge C. Data collection systems in ART must follow the pace of change in clinical practice. Hum Reprod 2016; 31:2160-3.

47. Regulamento (EU) 2016/679 do Parlamento Europeu e do Conselho de 27 de abril de 2016 relativo à proteção das pessoas singulares no que diz respeito ao tratamento de dados pessoais e à livre circulação desses dados e que revoga a Diretiva 95/46/CE (Regulamento Geral sobre a Proteção de Dados). Jornal Oficial da União Europeia, 2016. p. 119/1-/88. 
48. Higgs E. UK birth registration and its present discontents. Reprod Biomed Soc Online 2018; 5:35-7.

49. Ethics Committee of the American Society for Reproductive Medicine. Financial compensation of oocyte donors: an Ethics Committee opinion. Fertil Steril 2016; 106:e15-e9.

50. Kalampalikis N, Doumergue M, Zadeh S, French Federation of CECOS. Sperm donor regulation and disclosure intentions: results from a nationwide multi-centre study in France. Reprod Biomed Soc Online 2018; 5:38-45.

51. Silva S, Veloso L, editores. Representações jurídicas das tecnologias reprodutivas: contributos para uma reflexão. Porto: U. Porto Edições; 2009.

52. Allebrandt D. Entre movimento e interdição: novas tecnologias reprodutivas conceptivas postas em prática. In: Brum CK, da Silva e Sá GJ, organizadores. Entre poderes nativos e saberes ativos: antropologia e direitos humanos. Santa Cruz do Sul: Edunisc; 2009. p. 92-110.

53. Harper JC, Kennett D, Reisel D. The end of donor anonymity: how genetic testing is likely to drive anonymous gamete donation out of business. Hum Reprod 2016; 31:1135-40.
54. Ravelingien A, Provoost V, Pennings G. Creating a family through connection websites and events: ethical and social issues. Reprod Biomed Online 2016; 33:522-8.

55. ESHRE Task Force on Ethics and Law, Pennings G, de Wert G, Shenfield F, Cohen J, Tarlatzis B, et al. ESHRE Task Force on Ethics and Law 12: oocyte donation for non-reproductive purposes. Hum Reprod 2007; 22:1210-3.

56. Pennings G, de Mouzon J, Shenfield F, Ferraretti AP, Mardesic T, Ruiz A, et al. Socio-demographic and fertility-related characteristics and motivations of oocyte donors in eleven European countries. Hum Reprod 2014; 29:1076-89.

57. Campolina AG, Soárez PC, Amaral FV, Abe JM. Análise de decisão multicritério para alocação de recursos e avaliação de tecnologias em saúde: tão longe e tão perto? Cad Saúde Pública 2017; 33:e00045517.

58. Ávila MB. Direitos sexuais e reprodutivos: desafios para as políticas de saúde. Cad Saúde Pública 2003; 19:S465-9.

59. Menegon VSM. Novas tecnologias reprodutivas conceptivas: questões e desafios. Cad Saúde Pública 2004; 20:1434-6. 


\section{Abstract}

Awareness of the discussion surrounding the social and ethical challenges regarding gamete donation is crucial for good governance of assisted reproduction techniques. In this article, we analyze the topics that guided the debate in the Portuguese ethics organizations, discussing their connections with themes addressed internationally. To that end, in March 2018, we systematically searched the websites of the National Council of Medically Assisted Procreation and of the National Ethics Council for Life Sciences. We carried out a thematic content analysis of 25 documents. Results indicate that the debate was focused on accessibility, anonymity and donors' compensation and, to a lesser extent, on professional responsibilities. We observed heterogeneous positions and tensions between multiple rights and ethical principles associated with recipients, donor-conceived individuals and donors. These invoke three similar arguments: the scarcity of scientific evidence; experiences from other countries; and regulations from in international entities. Literature addressed additional topics, namely: a double track that combines donor anonymity/identification; the implementation of reproduction registries for recipients and donors; limits to the genetic screening of donors; donations by family members/acquaintances; and donors' role in decisions regarding the fate of cryopreserved embryos and in choosing the characteristics of recipients of their gametes. There is room to expand the debate and to promote research on the social and ethical implications of gamete donation, considering the participation of all citizens.

Assisted Reproductive Techniques; Bioethics; Donor Conception; Community Participation; Governance

\section{Resumen}

Conocer la discusión en torno a los desafíos sociales y éticos de la donación de gametos es fundamental para el buen gobierno de las técnicas de reproducción asistida. En este artículo se analizan los temas que orientaron el debate en las organizaciones de ética portuguesas, discutiendo sus conexiones con los temas abordados internacionalmente. Para este fin, en marzo de 2018, investigamos sistemáticamente las páginas webs del Conselho Nacional de Procriação Medicamente Assistida y del Conselho Nacional de Ética para as Ciências da Vida. Asimismo, procedimos al análisis de contenido temático de 25 documentos. Los resultados indican que el debate se centró en la accesibilidad, anonimato y compensación de donadores y, en menor extensión, en las responsabilidades profesionales. Se observaron posicionamientos heterogéneos $y$ tensiones entre múltiples derechos y principios éticos, asociados a receptores, a personas nacidas gracias a la donación de gametos y a donadores. Estos tienen en común tres alegaciones: la escasez de evidencias científicas; las experiencias de otros países; y las regulaciones procedentes de entidades internacionales. En el literatura se abordan temas adicionales, en particular: una vía doble que conjugue anonimato/identificación de donadores; implementación de sistemas de registro reproductivo para receptores y donadores; limites del rastreo genético a donadores; donación por familiares/conocidos; y el papel de los donadores en la decisión respecto al destino de embriones criopreservados $y$ en la elección de las características de los receptores de sus gametos. Existe espacio para abrir más el debate y promover la investigación en torno de las implicaciones sociales y éticas de la donación de gametos, considerando la participación de todos los ciudadanos.

Técnicas Reproductivas Assistidas; Bioética; Concepción de Donantes; Participación de la Comunidad; Gobernaza
Recebido em 21/Jun/2018

Versão final reapresentada em 11/Out/2018 Aprovado em 25/Out/2018 